\title{
Vasoactive Intestinal Polypeptide Stimulation of Cyclic AMP Formation in Rat Central Nervous System
}

\author{
Toshio KANEKO, SeISHi NAKAYA ${ }^{1}$, Shiro SAITO ${ }^{2}$, \\ Noboru YANAIHARA ${ }^{3}$ AND HiRoshi OKA ${ }^{4}$ \\ The 3rd Department of Internal Medicine, Yamaguchi University \\ School of Medicine, Ube., The 1st Department of Surgery, Kobe \\ University School of Medicine, Kobe ${ }^{1}$., Clinical Laboratory, \\ Tokushima University School of Medicine Tokushima2., \\ Laboratory of Bioorganic Chemistry, Shizuoka College \\ of Pharmacy, Shizuoka ${ }^{3}$, and The 1st Department \\ of Medicine, Faculty of Medicine, University \\ of Tokyo, Tokyo ${ }^{4}$.
}

\begin{abstract}
Synopsis
Vasoactive intestinal polypeptide (VIP) stimulated cyclic AMP formation in the anterior pituitary, hypothalamus, pons and cerebral medulla of rat in vitro.

The concentration of VIP above $10^{-7} \mathrm{M}$ significantly raised cyclic AMP level of these tissues with dose-dependency and the maximum stimulation of cyclic AMP formation was obtained at $5 \mathrm{~min}$ incubation. This stimulatory effect of VIP was not inhibited by propranolol or somatostatin.

However, no enhancement of hormone release from the anterior pituitary or hypothalamus into the incubation medium by VIP was observed.

These results suggest that VIP may act through adenylate cyclase in specific areas of rat central nervous system independent of $\beta$-adrenergic receptor, but it may not necessarily be related to hormone release from the anterior pituitary or hypothalamus.
\end{abstract}

Vasoactive intestinal polypeptide (VIP), originally isolated from the small intestine by Said and Mutt (1970, 1972), has been demonstrated to have potent and diverse effects on the cardiovascular and gastrointestinal systems. Based on the development of an immunoassay method for VIP, Bryant and co-workers (1976) reported first the presence of immunoreactive VIP in the central nervous system of man and pig. Said and Rosenberg (1976) also demonstrated VIP immunoreactivity in the clonal cell lines of neuronal and glial origin, and they suggested a possible dual role for VIP as a gastrointestinal hormone and a neurotrans-

This work was supported in part by grants (No. 457591 and 337003) from the Ministry of Education, Science and Culture, Japan. mitter substance.

On the other hand, Schwartz et al. (1974), had reported that VIP stimulated cyclic AMP production in ileal mucosa and caused the net secretion of both sodium and chloride in stripped ileum of the rabbit.

These results prompted us to investigate the physiological role and mechanism of action of VIP in the central nervous system.

This paper presents the results related to the effect of VIP on the cyclic nucleotide concentration in various areas of therat central nervous system in vitro.

\section{Materials and Methods}

VIP was synthesized in solution according to the method previously described (Yanaihara et al., 1977). 
and its purity was examined by thin layer chromatography, amino acid analysis and isoelectric focussing by comparing with natural porcine VIP.

The other peptides used in the experiments, porcine motilin, bombesin, substance $\mathrm{P}$, human gastrin I, were also synthesized in solution and their physicochemical and biological characteristics examined.

Male Wistar rats weighing $150-170 \mathrm{~g}$ were killed by decapitation and the whole brain and pituitary gland were quickly removed and then each area was isolated. After preincubation at $37^{\circ} \mathrm{C}$ for $30 \mathrm{~min}$ in Krebs-Ringer bicarbonate buffer containing $0.1 \%$ glucose and gassed with $95 \% \mathrm{O}_{2}-5 \% \mathrm{CO}_{2}$, the tissues were transferred into the same fresh buffer containing $5 \mathrm{~mm}$ theophylline, $0.1 \%$ bovine serum albumin and a suitable amount of VIP and were further incubated. The tissues were immediately frozen after the final incubation and homogenized with $6 \%$ TCA in a small conical homogenizer. The supernatant of the homogenate was extracted with water-saturated ether and lyophilized. The residue was dissolved in an appropriate volume of Tris- $\mathrm{HCl}$ buffer, $\mathrm{pH} 7.4$ and used for the determination of cyclic AMP and cyclic GMP. Cyclic AMP was assayed by the competitive protein binding method of Gilman (1970), and cyclic GMP was determined by the specific radioimmunoassay.

Hormone released from the anterior pituitary or hypothalamus into the incubation medium was measured by the specific radioimmunoassay system.

\section{Results}

Table 1 shows the effect of VIP on cyclic AMP formation in various areas of the rat central nervous system. VIP stimulated cyclic AMP formation of the anterior pituitary, hypothalamus, pons and cerebral medulla, but it did not increase the cyclic APM concentration of the posterior pituitary, cerebellum and cerebral cortex.

The other synthetic peptides tested in the experiments (porcine motilin, bombesin, substance $\mathbf{P}$ and human gastrin-I) did not change the cyclic AMP concentration in the rat anterior pituitary. In the hypothalamus and cerebral medulla, the same results were obtained. Although VIP stimulated cyclic AMP production in the rat anterior pituitary, it did not change the cyclic GMP level of the anterior pituitary (Table 2).

VIP at high concentrations above $10^{-7} \mathrm{M}$
Table 1. VIP $\left(10^{-7} \mathrm{M}\right)$ stimulation of cyclic AMP formation in various areas of rat central nervous system for $5 \mathrm{~min}$ incubation.

\begin{tabular}{lcc}
\hline \multicolumn{1}{c}{ Tissue } & \multicolumn{2}{c}{ Cyclic AMP } \\
& Control & VIP \\
& $12.9 \pm 2.5$ & $27.2 \pm 5.0^{*}$ \\
& $7.3 \pm 0.8$ & $6.8 \pm 0.8$ \\
Anterior pituitary & $10.9 \pm 1.3$ & $17.2 \pm 0.9^{*}$ \\
Posterior pituitary & $3.4 \pm 0.3$ & $4.7 \pm 0.7^{* *}$ \\
Hypothalamus & $3.2 \pm 0.3$ & $2.8 \pm 0.2$ \\
Pons & $7.2 \pm 2.3$ & $8.2 \pm 1.1$ \\
Cerebellum & $2.4 \pm 0.3$ & $4.6 \pm 0.6^{*}$ \\
Cerebral cortex & & \\
Cerebral medulla & &
\end{tabular}

$* \mathrm{p}<0.01, \quad * * \mathrm{p}<0.05$.

Table 2. Effects of various peptides on cyclic AMP and cyclic GMP levels in the rat anterior pituitary. Concentration of each peptide: $10^{-7} \mathrm{M}, 5 \mathrm{~min}$ incubation.

\begin{tabular}{lcc}
\hline \hline & $\begin{array}{c}\text { Cyclic AMP } \\
\text { (pmol/mg. prot.) }\end{array}$ \\
\hline Control & $7.7 \pm 0.5$ & $0.46 \pm 0.04$ \\
VIP & $12.3 \pm 0.5^{*}$ & $0.52 \pm 0.04$ \\
Motilin & $7.1 \pm 0.6$ & $0.46 \pm 0.03$ \\
Bombesin & $7.8 \pm 0.6$ & $0.42 \pm 0.04$ \\
Substance P & $7.0 \pm 0.4$ & - \\
Gastrin & $7.5 \pm 0.4$ & - \\
\hline * $<<0.01$. & &
\end{tabular}

stimulated cyclic AMP formation significantly and at the maximum stimulation the peptide increased the cyclic AMP concentration to about four times the control value. This stimulatory effect of VIP reached its maximum at $5 \mathrm{~min}$ incubation and was then gradually reduced (Fig. 1).

The $\beta$-adrenergic blo cking agent (propranolol, $10^{-4} \mathrm{M}$ ) did notinhibit the stimulation of cyclic AMP formation induced by VIP in the anterior pituitary and hypothalamus.

Somatostatin $\left(7 \times 10^{-6} \mathrm{M}\right)$ decreased the basal and stimulated level of cyclic AMP induced by $\mathrm{TRH}, \mathrm{LH}-\mathrm{RH}$ or prostaglandin in the anterior pituitary as reported previously (Kaneko et al., 1974), but it did not inhibit the stimulation of cyclic AMP 

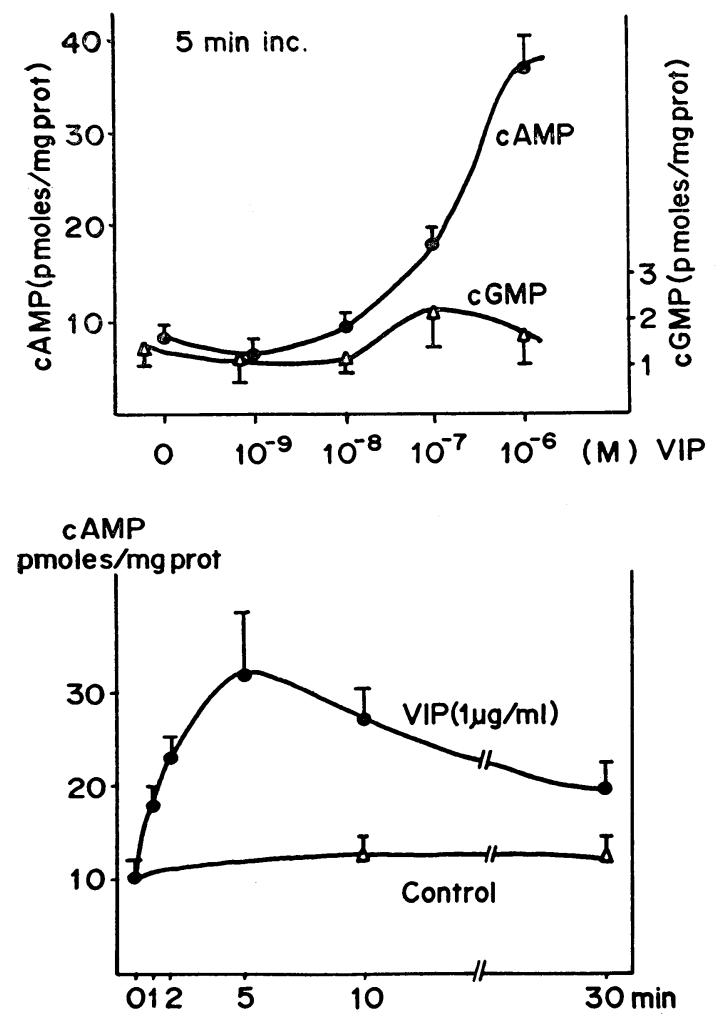

Fig. 1. Dose response and time course curve of the effect of VIP on cyclic AMP formation in rat anterior pituitary.

production by VIP in the gland (Fig. 2). The same phenomena were observed in the hypo- thalamus.

Table 3 demonstrates the effect of VIP on hormone release into the incubation medium from the anterior pituitary or hypothalamus. Under our experimental conditions, no significant enhancement of the hormone release from the anterior pituitary or hypothalamus by VIP was observed.

\section{Discussion}

Recently, the presence of many peptides isolated from the intestine has been demonstrated in the central nervous system by specific immunochemical methods, and pos-

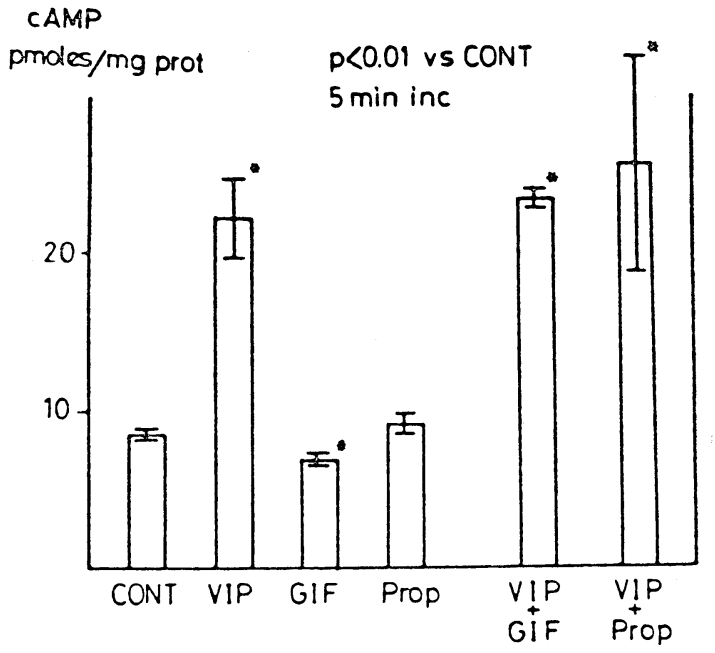

Fig. 2. Effect of somatostatin $\left(7 \times 10^{-6} \mathrm{M}\right)$ and propranolol $\left(10^{-4} \mathrm{M}\right)$ on VIP $\left(10^{-7} \mathrm{M}\right)$ stimulation of cyclic AMP production in rat anterior pituitary. GIF : somatostatin.

Table 3. Hormone release from the anterior pituitary or hypothalamus by VIP $\left(10^{-7} \mathrm{M}\right)$ for $60 \mathrm{~min}$ in vitro.

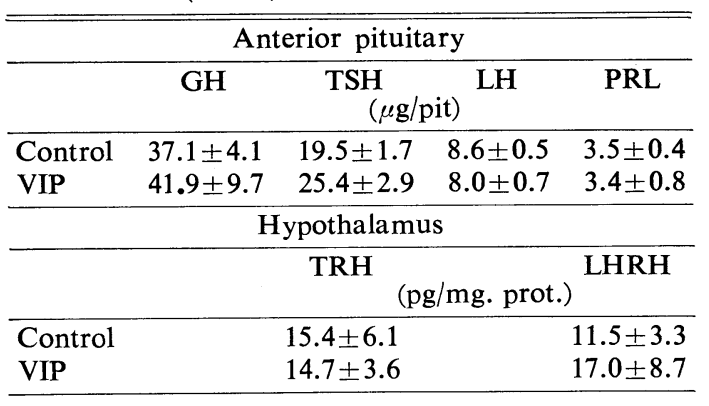

sibility as a neurotansmitter with some peptides was suggested. However, the exact function and mechanism of actionof these peptides in the central nervous system remain to be clarified.

The stimulatory effect of VIP on cyclic AMP formation in the intestine reported by Schwartz et al. prompted us to investigate the action of this peptide on cyclic nucleotide level of the various areas in the central nervous system.

As shown in table 1 and 2, VIP stimu- 
lated significantly cyclic AMP formation in specific areas of the rat central nervous system, but had no affect on cyclic GMP concentration in these tissues. The synthetic peptides, porcine motilin, bombesin, substance $\mathrm{P}$ and human gastrin-I, did not show any stimulatory or inhibitory effect on cyclic AMP and cyclic GMP concentrations in the anterior pituitary or other tissues (not shown in the table), although species variation of the amino acid sequence of the peptide hormones examined may or may not exist. VIP raised ihe cyclic AMP level not only in the anterior pituitary, but also in the hypothalamus, pons and cerebral medulla. The stimulation of cyclic AMP formation induced by VIP in the rat anterior pituitary was observed with dose-dependency and peaked at $5 \mathrm{~min}$ incubation and then decreased gradually.

The $\beta$-adrenergic blocking agent $\left(10^{-4} \mathrm{M}\right.$ of propranolol) did not inhibit a VIP effect on cyclic AMP in the gland as shown in Fig. 2 , indicating that VIP does not act through the $\beta$-adrenergic receptor.

Somatostatin, which inhibits the secretion or action of many peptide hormones, lowered the basal and stimulated level of cyclic AMP induced by TRH, LH-RH or prostaglandin in the anterior pituitary as reported previously (Kaneko et al., 1974), but it did not inhibit the stimulatory action of VIP on cyclic AMP formation in the anterior pituitary or in the hypothalamus. As TRH and LH-RH stimulated cyclic AMP formation and enhanced hormone release from the anterior pituitary respectively, these results suggest the possibility that VIP might stimulate the release of a hormone or hormones from the anterior pituitary or hypothalamus through the activation of adenylate cyclase.

The results shown in the table 3 demonstrated the negligible effect of VIP on hormone release into the incubation medium from the anterior pituitary or hypothalamus for $60 \mathrm{~min}$ incubation. Under our experimental conditions, even after 60 min incubation or longer, VIP did not significantly stimulate the release of $\mathrm{GH}, \mathrm{TSH}, \mathrm{LH}$, prolactin, or FSH and ACTH (not shown in the table) from the anterior pituitary. In the hypothalamus, no enhancement of secretion of TRH and LH-RH and also somatostatin (not shown in the table) by VIP was observed.

These results suggest that the action of VIP in stimulating cyclic AMP formation in the specific areas of the rat central nervous. system is not through $\beta$-adrenergic receptor and may not necessarily be related to the hormone release from the tissues.

\section{References}

Bryant, M. G., S. R. Bloom, S. M. Polak, R. M. Albuquerque, I. Modlin and A. G. E. Pears (1976). Lancet 1, 991.

Gilman, A. G. (1970). Proc. Natl. Acad. Sci. U.S.A. 67, 305.

Kaneko, T., H. Oka, M. Munenura, S. Suzuki, H. Yasuda and T. Oda (1974). Biochem. Biophys. Res. Commun. 61, 53.

Said, S. I. and V. Mutt (1970). Science 169, 1217.

Said, S. I. and R. N. Rosenberg (1976). Ibid, 192, 908.

Schwartz, C. J., D. V. Kimberg, H. E. Sherin, M. Field and S. I. Said (1974). J. Clin. Invest. 54, 536. Yanaihara, N., M. Sakagami, H. Sato, K. Yamameto, T. Hashimoto, C. Yanaihara, Z. Ito, K. Yamaguchi and K. Abe (1977). Gastrointerology. $72,803$. 